\title{
Gênero e política no noticiário das revistas semanais brasileiras: ausências e estereótipos*
}

\author{
Flávia Biroli**
}

\begin{abstract}
Resumo
$\mathrm{O}$ artigo analisa as relações entre gênero e política no noticiário das revistas semanais brasileiras Veja, Época e Carta Capital, em 2006 e 2007. Os dados permitem constatar a presença reduzida de mulheres no noticiário e a existência de estereótipos de gênero que remetem a compreensões do papel da mulher nas sociedades e de sua competência para atuar na vida pública. Por meio da análise das mulheres políticas que tiveram maior visibilidade no período analisado - Heloisa Helena, Marta Suplicy e Dilma Rousseff -, discute representações de feminilidade e de masculinidade, do privado e do público, que atribuem sentidos à presença diferenciada de homens e mulheres na política e na mídia.
\end{abstract}

Palavras-chave: Gênero, Mídia, Política, Representação, Estereótipos.

\footnotetext{
* Recebido para publicação em março de 2009, aceito em novembro de 2009.

** Professora do Instituto de Ciência Política da Universidade de Brasília. Pesquisadora do CNPq. fbiroli@terra.com.br
}

cadernos pagu (34), janeiro-junho de 2010:269-299. 
Gênero e política

Gender and Politics in Brazilian News Magazines: Absences and Stereotypes

\begin{abstract}
The present article analyses the relationship between gender and politics in Brazilian weekly news magazines Veja, Época e Carta Capital, in 2006 and 2007. Data allows a discussion about the scant presence of women in news magazines and the presence of gender stereotypes that refer to understandings of women's role and their competence to act in public life. Analysing women who had most visibility within the chronological limits of the research Heloisa Helena, Marta Suplicy e Dilma Rousseff -, it discusses representations of femininity and masculinity, private and public, that give specific meanings to the presence of men and women in politics and the media.
\end{abstract}

Key Words: Gender, Media, Politics, Representation, Stereotypes. 
Flávia Biroli

\section{Introdução}

Os movimentos feministas e a crítica acadêmica têm explicitado há décadas o caráter político das relações de gênero ${ }^{1}$. Um de seus muitos aspectos é a ausência de mulheres, ou sua presença reduzida, em espaços que oferecem prestígio e recursos materiais e simbólicos eficazes para intervir na sociedade. Um número maior de mulheres no campo político ou jornalístico - e aqui refiro-me aos noticiários, e não às redações - não significa, necessariamente, a incorporação de discursos e práticas feministas ou mesmo um deslocamento mínimo em relação às práticas convencionais. Sua ausência, no entanto, demonstra que os obstáculos e dificuldades para a inclusão dos diferentes indivíduos e grupo sociais nesses espaços não têm o mesmo impacto sobre homens e mulheres. Esses obstáculos, por sua vez, podem estar relacionados, de maneira complexa, ao silenciamento e à estigmatização de perspectivas e experiências socialmente relevantes.

A sub-representação das mulheres na política leva, ao mesmo tempo, a dois conjuntos de problemas. Um deles, mais amplo, é relativo ao funcionamento das democracias liberais, nas quais a igualdade formal convive com formas sistemáticas de exclusão de alguns grupos sociais. $\mathrm{O}$ outro remete, de maneira mais específica, à manutenção das mulheres em posições subalternas em sociedades nas quais o direito à participação política foi universalizado $e$ não existem restrições formais a sua inclusão nas mais diversas esferas, entre elas a política. A mídia pode ser pensada como esfera que participa ativamente da reprodução ou da transformação de práticas, valores e instituições que configuram as formas atuais da representação $e$ da

1 Este artigo apresenta dados produzidos no âmbito das pesquisas "Determinantes de gênero e visibilidade midiática" (CNPq 45/2005, com Luis Felipe Miguel) e "Gênero e política na mídia brasileira" (CNPq 61/2005) e contou com o apoio de bolsas PQ e IC. 
Gênero e política

participação política nas democracias e legitimam as formas assumidas pelas relações de gênero.

Um dos eixos deste artigo é a constatação da presença reduzida e marginal das mulheres no noticiário político das principais revistas semanais brasileiras, discutindo suas razões $e$ implicações. Mas as posições distintas ocupadas por homens $e$ mulheres no noticiário não se assentam, de maneira direta, sobre a mera inclusão ou exclusão em espaços de poder e visibilidade. É preciso discutir as formas assumidas por essa presença, analisando as representações - de feminilidade e de masculinidade, do privado e do público - que atribuem sentidos à presença diferenciada de homens e mulheres na política e no noticiário. Assim, o objetivo deste trabalho é também expor e discutir a convivência entre a presença reduzida das mulheres no noticiário das revistas semanais brasileiras e a existência de estereótipos de gênero que remetem a compreensões menos ou mais convencionais do papel da mulher nas sociedades e de sua competência para atuar na vida pública.

Partindo de um amplo mapeamento da presença de homens e mulheres no noticiário político de telejornais e revistas semanais $^{2}$, este artigo analisa mais detidamente a presença das três mulheres citadas com maior freqüência no noticiário político das revistas semanais Veja, Época e Carta Capital, nos anos de 2006 e 2007: Heloisa Helena, Marta Suplicy e Dilma Rousseff.

O problema central que determina a abordagem proposta é o de que à sub-representação das mulheres nos espaços formais de poder político soma-se sua sub-representação na mídia, especialmente no noticiário político, foco da pesquisa. Essa presença reduzida é, por sua vez, marcada por estereótipos de gênero e vinculada a posições de menor prestígio, reforçando a posição marginal das mulheres na política. Entende-se que a discussão sobre a sub-representação de mulheres nos espaços de

${ }^{2}$ Os resultados foram parcialmente apresentados em Miguel e Biroli (2008). 
poder deve levar em conta a forma como a mídia representa a política e, nela, as relações de gênero.

As hipóteses centrais são: (1) as mulheres são, predominantemente, invisíveis no noticiário político; (2) a visibilidade feminina no noticiário político é concentrada em algumas poucas mulheres $e$ produzida por filtros que reafirmam, de múltiplas maneiras, as separações tradicionais que associam as mulheres à esfera doméstica e íntima, à emotividade e ao corpo.

$\mathrm{O}$ desinteresse pela política, a falta de habilidade para o exercício de cargos públicos e o não-pertencimento à esfera política são, assim, conectados em um conjunto de discursos que atendem a uma regularidade sem que se apresentem de forma homogênea. A oposição entre, de um lado, feminino e espaço privado, e, de outro, masculino e espaço público, discutida em estudos como os das cientistas políticas Carole Pateman (1993) e Susan Okin (1998, 1989), está na base desses estereótipos, confirmando divisões e hierarquias que colaboram para a marginalização das mulheres da e na esfera política.

É importante sublinhar que, na perspectiva aqui assumida, não se trata de uma relação causal entre o campo político e o campo da mídia - em que as formas assumidas pela representação feminina na mídia seriam simplesmente um "espelho" da sub-representação na política ou, em sentido inverso, em que a sub-representação na política seria um efeito direto da pouca visibilidade das mulheres na mídia ou dos filtros que as mantêm em posição de pouca relevância nos noticiários.

Os estereótipos de gênero presentes na mídia devem ser entendidos como produtos de uma dinâmica social mais ampla, que envolve a determinação de papéis diferenciados, e hierarquicamente distintos, para homens e mulheres. Por outro lado, esses estereótipos são reproduzidos de acordo com o modus operandi específico dos meios de comunicação de massa, que envolve as rotinas de produção do noticiário jornalístico $e$ as perspectivas sociais dos jornalistas. Esses estereótipos consistem, assim, em narrativas cristalizadas que são ativadas na medida em 
Gênero e política

que os holofotes se voltam para as mulheres políticas. Sua ancoragem em compreensões convencionais do feminino e do masculino naturaliza a ausência de mulheres de espaços $e$ posições de maior poder. Naturaliza, também, o fato de que as tensões entre a atuação política e a vida privada e afetiva sejam relevantes para a trajetória e a imagem pública das mulheres, enquanto são potencialmente inexistentes para os homens.

\section{Público, privado e estereótipos de gênero}

A naturalização da exclusão das mulheres da esfera pública $e$, particularmente, dos cargos políticos eletivos, vem sendo um fator de legitimação da política como "negócio de homens". As mulheres não se interessariam pelos debates políticos $e$, menos ainda, por participar da política institucional porque estariam, "naturalmente", voltadas para o que lhes seria mais caro: a vida privada, a esfera doméstica, a maternidade. A crítica feminista e a atuação política a ela correspondente confrontam-se com práticas $e$ valores patriarcais que se atualizam, tendo como um de seus eixos a afirmação do desinteresse feminino pela política, o silêncio sobre a atuação pública das mulheres $e$, no limite, a reprodução de estereótipos de gênero.

As definições assumidas pela oposição público-privado na modernidade têm o gênero como um elemento central. Para Pateman, em estudo que se tornou referência central para esse debate,

A esfera privada, feminina (natural) e a esfera pública, masculina (civil) são contrárias, mas uma adquire significado a partir da outra, e o sentido de liberdade civil da vida pública é ressaltado quando ele é contraposto à sujeição natural que caracteriza o domínio privado (Pateman, 1993:28).

A partir da análise das teorias contratualistas, a autora ressalta que é o direito patriarcal (moderno) dos homens que 
constitui as noções de indivíduo e universalidade que estruturam a compreensão liberal da esfera pública. A subordinação das mulheres aos homens, tanto na vida privada quanto na pública, seria o elo que estabelece as relações entre as duas esferas, fazendo com que, na modernidade, a subordinação feminina seja inseparável da liberdade e autonomia dos "cidadãos". 3 O feminismo desafia a suposição presente em grande parte da teoria política de que a esfera da família e da vida pessoal é tão separada e distinta do resto da vida social que essas teorias poderiam legitimamente ignorá-la (Okin, 2008:122-3). O público e o privado são vistos como partes interligadas de um ciclo de desigualdades entre os sexos (Okin, 1989:133), o que tem implicações para a análise das tradições e abordagens teóricas "a maior parte das teorias anglo-americanas da justiça é, em grande medida, sobre homens com mulheres em casa" (Okin, 1989:110). ${ }^{4}$ Ao mesmo tempo, esse debate permite a revisão de pressupostos presentes em setores do movimento feminista que vinculam a participação da mulher na vida pública a uma "sensibilidade moral especial, desenvolvida na esfera doméstica" (Id. ib).

A posição assumida aqui está de acordo com a visão de Iris M. Young de que as diferenças de gênero são estruturais e, como tais, demarcam possibilidades específicas de atuação e excluem outras. Trata-se, assim, de operar não com uma condição feminina baseada em atributos morais ou em interesses unificados pelo sexo, mas com um conjunto de perspectivas que constituem $e$

3 A análise de Pateman em seu livro mais conhecido, $O$ contrato sexual, de 1988, e em outras obras em que trabalha a noção de patriarcado para a crítica às hierarquias de gênero, recebeu muitas críticas. Destaco dois eixos: a crítica ao uso do conceito de patriarcado para a análise das sociedades modernas, tidas como pós-patriarcais, e a crítica à compreensão das relações de gênero por meio da dualidade entre dominação e subordinação. Vale conferir a discussão feita por Nancy Fraser (1997), que se concentra sobretudo nesse último eixo.

4 Para uma análise sistemática da posição crítica de Okin e de seus limites, cf. Biroli (2010). 
Gênero e política

diferenciam o posicionamento das mulheres em relações de poder marcadas centralmente pelo gênero. Para Young (2000), cada perspectiva social é particular e parcial em relação ao campo social como um todo. Seu apagamento significaria, assim, o apagamento das trajetórias no que elas têm de politicamente significativo, na medida em que permitem que sejam vislumbrados aspectos da realidade social que não se tornam visíveis, da mesma maneira, pela expressão das trajetórias e experiências de outros grupos. ${ }^{5}$

Explicitada essa posição, vale destacar que esse debate remete a um problema que constitui tensões teóricas e políticas com as quais procuramos lidar. Podemos observar, com Pateman, que tanto a exclusão das mulheres da vida política quanto sua inclusão estão historicamente associadas a suas diferenças em relação aos homens - "as mulheres vêm sendo excluídas e incluídas como mulheres" (Pateman, 1990:60). A contraposição à universalidade, que constituiria as categorias liberais de indivíduo e cidadão, ocultando as relações de gênero que demarcam espaços e possibilidades, implicaria, para a autora, na elaboração de concepções "sexualmente diferenciadas" de cidadania, reconhecendo as mulheres como mulheres (Pateman, 1990; Pateman, 1986 apud Mouffe, 2005:80).

É preciso levar em consideração que o recurso aos papéis sociais tradicionalmente reservados às mulheres pode ser, ao mesmo tempo, um obstáculo a uma atuação política mais destacada $e$ uma estratégia de diferenciação $e$ ação política por parte das mulheres.

A noção de perspectiva em Young, acima mencionada, permite levar em conta essa ambigüidade, incorporando, porém, as críticas feitas por Mouffe (2005) à própria Pateman. Para

\footnotetext{
5 Para análises que recorrem ao conceito de perspectiva para discutir a pluralidade nos meios de comunicação, cf. Miguel e Biroli (2009 e 2010). Vale ressaltar, ainda, a importância do debate sobre "política de presença" (Phillips, 1995) para as hipóteses aqui trabalhadas.
} 
Mouffe, a proposta de uma cidadania (ou atuação política, no foco desta pesquisa) que reconheça a feminilidade se ancora na identificação das mulheres com a maternidade, levando à afirmação de alguma essência que caracterizaria as mulheres como mulheres. Para a autora, esse argumento pode se contrapor de maneira eficaz à universalização e abstração que definem as categorias liberais de cidadania $e$ individualidade, mas não é capaz de desconstruir a oposição homem/mulher e os sentidos a ela associados.

Ao discutirmos a presença de mulheres no noticiário político, é preciso ter em mente (1) que se trata de pensar a presença de mulheres como uma potencialidade de ruptura com a oposição masculinidade/esfera pública versus feminilidade/esfera privada, uma vez que essa presença pode significar uma ruptura com a categoria supostamente universal e abstrata de indivíduo central ao ideário político liberal, com as tensões entre inclusão $e$ exclusão que o constituem, mas (2) que a mera presença, quantitativamente falando, não indica por si só uma potencialidade de reconfiguração dessa oposição e das relações de gênero que ela embasa, daí a importância de se trabalhar a relação entre gênero e estereótipos. É neste último sentido que se considera que a presença (assimétrica) de homens e mulheres no noticiário, perpassada por estereótipos de gênero, pode significar a confirmação, pela mídia, de papéis hierarquicamente diferenciados para homens e mulheres.

\section{Gênero, mídia e política}

Os meios de comunicação de massa são aqui considerados aparatos técnicos de mediação simbólica que transformaram a natureza das interações sociais $e$ as percepções que indivíduos $e$ grupos têm de si mesmos e dos outros (Thompson, 1995). Os julgamentos e valores que organizam a experiência são confirmados, (re)produzidos e transformados pela mídia. Indivíduos e temas ganham relevância e são julgados, em maior 
Gênero e política

ou menor medida, por sua presença na agenda dos meios de comunicação de massa e por sua inserção em narrativas que atribuem sentido à experiência social. Mas essas narrativas não são homogêneas. Pode haver diferenças, e mesmo conflitos, entre valores e julgamentos dentro de um mesmo noticiário ou em diferentes espaços ou partes da programação em um mesmo veículo. Há, ainda, variações na apreensão, compreensão $e$ ativação dessas narrativas pelo público.

Por outro lado, pode-se trabalhar com a hipótese de que existem padrões organizando o noticiário na mídia de grande circulação. Isso ocorre porque a dinâmica atual de produção das notícias é marcada pelas formas institucionalizadas do campo da mídia e pelos interesses e perspectivas sociais dos jornalistas. $\mathrm{O}$ resultado é um noticiário repetitivo, em que os diferentes veículos $e$ produtos jornalísticos incorporam grades de relevância $e$ procedimentos comuns na escolha das fontes $e$ no acesso a informações, difundindo representações do campo político e dos agentes políticos que confirmam as formas atuais de distribuição de capital e reconhecimento naquele campo.

Nesse contexto - de produção de silêncios e de uma visibilidade que toma forma a partir de filtros comuns -, as representações sobre a feminilidade presentes na mídia podem reforçar uma série de estereótipos ligados aos papéis de gênero. Para Norris (1997:8), os enquadramentos predominantes na representação da atuação política das mulheres, nos quais se localizam, com variações, os estereótipos de gênero, são um produto das interações entre a mídia, as fontes dos noticiários e o público. ${ }^{6}$

Nesse sentido, uma questão a ser considerada é se as representações sobre masculinidade e feminilidade nos noticiários

${ }^{6}$ A partir do trabalho de Gaye Tuchman, Norris destaca que é preciso observar o modo como rotineiramente a mídia lida com as histórias que constituem as notícias, considerando a institucionalização dos enquadramentos pelas empresas, o treinamento e a cultura profissional, as práticas e valores ligados à produção da notícia. 
estão marcadas por associações tradicionais entre o que se entende por feminino e os papéis e expectativas relacionados à esfera privada $e$, no limite, à maternidade. É preciso considerar em que medida, de fato, esses estereótipos estão presentes no discurso jornalístico, como eixos centrais aos enquadramentos $e$ padrões discursivos em que se insere a atuação política feminina quando esta é visível. Estudos sobre a presença de lideranças femininas nos noticiários e sobre campanhas políticas de mulheres apontam para o fato de que as próprias candidatas podem lançar mão desses estereótipos para obter sucesso nas urnas e galgar posições, na mídia e na política (Iyengar et alii, 1997). Outros estudos concluem que a invisibilidade é o problema mais central quando se analisa a mídia noticiosa, mas que uma vez visíveis na mídia, não são predominantes representações estereotipadas $e$ enquadramentos negativos focados no gênero. ${ }^{7}$

Entende-se, como já foi dito, que a "mera presença" de vozes femininas no noticiário não garante deslocamentos em relação a práticas políticas e a discursos convencionais sobre a política e sobre as relações de gênero. Sua exclusão ou sua presença reduzida, marcada por estereótipos, indica, no entanto, que os filtros que definem quem estará presente no noticiário, e como estará presente, incidem diferentemente sobre homens $e$ mulheres.

Há ao menos três questões que precisam ser consideradas. Não é possível estabelecer uma correspondência entre a presença

$7 \mathrm{Em}$ pesquisa que analisa a cobertura de veículos norte-americanos às congressistas da 103 ${ }^{\text {a }}$ Legislatura, eleitas nas eleições de 1992 (Year of the woman), o problema encontrado, segundo Carroll e Shreiber (1997:145), diz respeito à omissão e não ao tratamento conferido às mulheres: "o problema principal não é tanto com a cobertura que existe, mas com a que não existe". Em conclusão que toca no problema da relação com temáticas e áreas de atuação, as autoras constatam que está ausente do noticiário a percepção de que as mulheres exercem papéis importantes não apenas quando legislam sobre saúde, aborto etc. A cobertura não aborda o envolvimento das mulheres, por exemplo, em debates relacionados ao comércio internacional, assuntos estrangeiros, reforma política. 
Gênero e política

de mulheres e uma "voz feminina". Tal correspondência levaria a uma essencialização do feminino e a uma desconsideração da complexidade do conceito de perspectiva (Young, 2000). Em segundo lugar, não existe uma correlação necessária entre presença feminina e "voz feminista", aqui entendida no sentido da materialização, nos noticiários, de discursos críticos às relações de gênero hierárquicas e à oposição entre masculino/público $e$ feminino/privado. Isso significa, entre outras coisas, uma clareza em relação ao fato de que um aumento da presença de mulheres em esferas de poder $e$ visibilidade não implica, necessariamente, a promoção de perspectivas críticas às relações convencionais de gênero e, mesmo, ao problema específico da sub-representação das mulheres em espaços de poder.

Por último, a presença de homens e mulheres nos noticiários só pode ser considerada como uma representação dos lugares de enunciação (diversos) de homens e mulheres, inseridos em relações sociais concretas. Voltando ao conceito de perspectiva, tratam-se, no máximo, de representações, de simulacros dessas perspectivas, levando em consideração as posições concretas, estruturais, das mulheres em uma sociedade específica, em um dado momento. Se, do ponto de vista de uma análise do discurso (Pêcheux, 1997), entende-se que os processos discursivos são constituídos por lugares de enunciação que são a representação das posições sociais de destinador e destinatário, $e$ não suas posições sociais "concretas", ao analisar a mídia impressa isso implica levar em conta, no mínimo: (1) a assimetria entre os diversos níveis de autoria no jornalismo e o público como destinatário; (2) o modo como as projeções em relação a esse destinatário constituem o discurso jornalístico; (3) o modo como as relações entre os veículos e entre os próprios jornalistas constituem o discurso jornalístico; (4) as relações específicas entre as hierarquias no jornalismo e na política, que têm como um de seus aspectos a relação com as fontes; (5) a situação característica da mídia impressa na sociedade brasileira, em que temos elites sócioeconômicas situadas dos "dois lados" do processo discursivo, sem 
que isso signifique que tenhamos, necessariamente, a predominância de um dos sexos (dentro das redações ou entre os leitores).

Tendo em mente a complexidade das relações entre gênero, mídia e representação, a próxima seção apresenta e analisa dados que permitem constatar a presença reduzida de mulheres e discutir a persistência de estereótipos de gênero no noticiário das revistas semanais Veja, Época e Carta Capital.

\section{As revistas semanais $e$ o reforço às divisões e papéis tradicionais de gênero}

A sub-representação das mulheres é bastante acentuada no noticiário das revistas semanais analisadas (Veja, Época e Carta Capital). Elas são apenas $10,1 \%$ das personagens citadas no noticiário. O percentual de presença feminina cresce apenas entre os "populares", pessoas anônimas que são entrevistadas para dar colorido às reportagens, alcançando $37,8 \%$ das personagens citadas. As mulheres são $6,9 \%$ das personagens ligadas ao executivo, $8,6 \%$ das personagens ligadas ao legislativo, $12,7 \%$ daquelas ligadas ao judiciário e apenas $9,9 \%$ das personagens que são apresentadas como vozes "técnicas", ligadas a alguma competência específica e reconhecida (economistas, cientistas políticos, médicos, especialistas de áreas diversas). Entre os candidatos ao cargo de deputado federal, no noticiário do segundo semestre de 2006, 5,1\% são mulheres (contra 12,6\% de candidaturas femininas registradas no Tribunal Superior Eleitoral); entre os candidatos a senador, $7 \%$ são mulheres (contra $16,5 \%$ de candidaturas femininas registradas no Tribunal Superior Eleitoral) - nos dois casos, além do problema mais amplo da subrepresentação política das mulheres, inclusive em relação à cota de $30 \%$ entre as candidaturas apresentadas pelos partidos, temos a indicação de que existe um problema específico de subrepresentação das mulheres no noticiário político. ${ }^{8}$

8 Dados da pesquisa "Determinantes de gênero e visibilidade midiática". 
Gênero e política

A presença feminina é, ainda, concentrada em algumas poucas mulheres. Entre as personagens mais citadas no noticiário político das revistas Veja, Época e Carta Capital, em 2006 e 2007 (aquelas presentes em 70 ou mais matérias), não há nenhuma mulher. As mulheres presentes com maior freqüência são, em primeiro lugar, a senadora e então candidata à presidência pelo PSol Heloisa Helena. Em segundo lugar está Marta Suplicy, que no período da pesquisa disputava a indicação para concorrer ao governo estadual pelo PT. Derrotada, ocupou no período eleitoral o cargo de coordenadora da campanha presidencial de Lula no estado de São Paulo e no período pós-eleitoral assumiu o cargo de ministra do Turismo. A terceira mulher mais visível foi Dilma Rousseff, então ministra da Casa-Civil, que viria a ser candidata do PT nas eleições presidenciais de 2010. A personagem mais citada, entre homens e mulheres, em todos os períodos pesquisados, é o presidente Lula, seguido de Geraldo Alckmin, José Serra, José Dirceu e Fernando Henrique Cardoso.

Além de reduzida e concentrada em poucas mulheres, a presença feminina nos noticiários é acompanhada por estereótipos e compreensões marcadamente redutoras sobre a participação política feminina. Uma nota não assinada na seção "Contexto" da revista Veja, publicada em 26 de julho de 2006 (p.48), é um exemplo. Intitulada "Política é coisa de homem?", a nota explica que "de acordo com a lei eleitoral, os partidos políticos devem reservar $30 \%$ das vagas a que têm direito nas eleições para mulheres que querem ser candidatas". Essa explicação é acompanhada da afirmação de que a regra "não tem respaldo na realidade" porque "o interesse feminino pela política é muito menor do que o masculino". Segundo a revista, o fato de $88 \%$ dos candidatos a deputados federais nas eleições de 2006 terem sido homens permitiria constatar esse desinteresse - nada é dito, obviamente, sobre o fato de que esse percentual se amplia quando se trata de observar a representação dos candidatos homens nas revistas: no caso, aproximadamente $95 \%$ das candidaturas presentes no noticiário. 
Partimos dessas constatações para discutir como se configura a presença das três mulheres mais citadas no noticiário no período pesquisado, Heloisa Helena, Marta Suplicy e Dilma Rousseff. Para tanto, selecionamos todas as matérias em que essas três mulheres foram citadas, nas três revistas analisadas, ao longo de todo o ano de 2006 e do primeiro semestre de 2007. ${ }^{9}$ Além disso, para que fosse possível comparar a presença feminina à masculina também analisamos a presença do ministro Márcio Thomaz Bastos no mesmo período. A escolha por Bastos se deveu ao fato de que, em termos percentuais, o ministro tem uma visibilidade relativa semelhante à das mulheres mencionadas $e$, ainda, à hipótese de que poderia ser um contraponto significativo às representações das três personagens femininas analisadas. ${ }^{10}$

A distribuição das personagens entre as revistas analisadas não apresenta muitas diferenças. Heloisa Helena está mais presente em Veja, que concentra $38,7 \%$ de suas menções no material (contra 32,3\% em Carta Capital e 29\% em Época); Marta Suplicy tem sua presença ainda mais concentrada em Veja $(51,6 \%$, contra 29,7\% em Época e 18,8\% em Carta Capital). A presença de Dilma Rousseff acompanha a seqüência de Helena e Suplicy, com 43,4\% em Veja, 32,5\% em Época e 24,1\% em Carta Capital, enquanto a de Márcio Thomaz Bastos é a mais concentrada entre

9 Diferentemente dos dados anteriormente apresentados, que resultam da análise de três períodos de três meses em cada semestre, neste caso foram consideradas todas as edições das revistas ao longo dos três semestres.

${ }^{10}$ Consideradas as quatro personagens, foram analisadas 312 matérias - 93 relativas a Heloisa Helena, 83 a Dilma Rousseff, 72 a Márcio Thomaz Bastos e 64 a Marta Suplicy. ${ }^{10}$ Essas matérias estão distribuídas desigualmente entre os três períodos (semestres) analisados - 76,3\% da presença de Helena acontece no período eleitoral, enquanto Rousseff e Suplicy estão presentes de maneira mais concentrada no terceiro período da pesquisa, após as eleições $(48,19 \%$ das menções a Rousseff e 46,8\% das menções a Suplicy). A presença de Márcio Thomaz Bastos é maior no período eleitoral do que nos demais $(41,6 \%)$, mas é a que aparece distribuída de maneira mais equilibrada entre os períodos. 
Gênero e política

as personagens analisadas: $59,7 \%$ das menções estão na revista Veja, contra 31,9\% em Carta Capital e apenas 8,3\% em Época. ${ }^{11}$

A presença das quatro personagens pode, também, ser observada de acordo com seu destaque nas matérias (tabela 1):

Tabela 1

Centralidade das personagens nas matérias das revistas semanais brasileiras, 2006 e 2007.

\begin{tabular}{|l|l|l|l|l|}
\hline & Central & Secundária & $\begin{array}{l}\text { Apenas } \\
\text { mencionada }\end{array}$ & Total \\
\hline $\begin{array}{l}\text { Dilma } \\
\text { Rousseff }\end{array}$ & $25,3 \%(21)$ & $24,1 \%(20)$ & $50,6 \%(42)$ & $100 \%(83)$ \\
\hline $\begin{array}{l}\text { Heloisa } \\
\text { Helena }\end{array}$ & $38,7 \%(36)$ & $26,9 \%(25)$ & $34,4 \%(32)$ & $100 \%(93)$ \\
\hline $\begin{array}{l}\text { Marta } \\
\text { Suplicy }\end{array}$ & $17,2 \%(11)$ & $42,2 \%(27)$ & $40,6 \%(26)$ & $100 \%(64)$ \\
\hline $\begin{array}{l}\text { Márcio } \\
\text { T. Bastos }\end{array}$ & $20,8 \%(15)$ & $43,15(31)$ & $36,1 \%(26)$ & $100 \%(72)$ \\
\hline Total & $26,6 \%(83)$ & $33 \%(103)$ & $40,4 \%(126)$ & $100 \%(312)$ \\
\hline
\end{tabular}

Fonte: Pesquisa "Gênero e política na mídia brasileira".

Vale observar que a personagem mais citada, Heloisa Helena, também recebe mais destaque, tendo centralidade em $38,7 \%$ das matérias em que é mencionada. Esse dado, como se pode supor, tem relação direta com sua candidatura à Presidência da República nas eleições de 2006. No primeiro semestre de 2007,

${ }^{11}$ Vale observar que a concentração da presença de Márcio T. Bastos em Veja está relacionada ao fato de que, ao longo de 2006, ele é a principal voz em defesa do governo em matérias sobre escândalos. Veja concentra o maior número de reportagens sobre escândalos no governo Lula $167 \%$ das matérias sobre o tema publicadas pelas três revistas no período pesquisado, o que equivale a $9,2 \%$ do material publicado por Veja no período), enquanto Época apresenta um número reduzido (apenas $8,7 \%$ das matérias sobre o tema publicadas no período pesquisado, o que equivale a $1,9 \%$ do material publicado pela revista no período). 
ela praticamente desaparece do noticiário das revistas (está presente em apenas 3 ou $0,35 \%$ das 85 menções às personagens analisadas ao longo desse período e, em todos os casos, é apenas mencionada), o que é relevante para se pensar quais são os critérios que definem a visibilidade no noticiário político.

No que se refere aos estereótipos de gênero presentes no noticiário, a pesquisa "Determinantes de gênero, visibilidade midiática e carreira política no Brasil" mostrou uma correlação relevante entre o sexo das personagens e as temáticas às quais estão vinculadas. Os homens, além de mais presentes quantitativamente em todo o noticiário, concentram sua presença em temas que têm maior destaque, ocupando posições mais centrais no noticiário das revistas. Em $28,1 \%$ dos casos, sua presença é no noticiário político, contra $14 \%$ da presença das mulheres; $3,9 \%$ dos homens estão presentes no noticiário econômico, contra $1,5 \%$ das mulheres. Por outro lado, as mulheres têm maior concentração no noticiário de faits-divers ( $49,8 \%$ contra $31,8 \%$ dos homens), cidades ( $4,3 \%$ contra $1,5 \%$ dos homens) e educação ( $1,1 \%$ contra $0,4 \%)$. Vale ressaltar que as duas primeiras, faits-divers e cidades, são as categorias temáticas em que se encontra o maior número de "populares", personagens aos quais não é associada nenhuma competência específica. ${ }^{12}$

Em outra dimensão desses estereótipos, também relacionada diretamente à representação de mulheres e homens no noticiário, as análises realizadas permitiram observar a presença de enunciados que caracterizam as personagens, distribuídos em três eixos: (1) personalidade e feminilidade; (2) corporalidade; (3) vida privada.

Vale ressaltar que, neste ponto, os aspectos quantitativos perdem relevância. Entende-se que a presença de enunciados que

${ }^{12}$ Para mais discussões sobre a relação entre gênero e áreas temáticas no noticiário, cf. Miguel e Biroli (2008); para dados sobre a vinculação a áreas temáticas na atuação política das deputadas federais no Brasil, cf. Biroli e Mello (2008) e Pinheiro (2007). 
Gênero e política

explicitam ou indicam uma problemática de gênero, mesmo que estatisticamente seja pouco relevante, permite discutir aspectos significativos das divisões e hierarquias de gênero nos noticiários e na política. Essa posição se acentua quando essas marcas (estereótipos de gênero) são analisadas tendo-se em mente os dados relativos à sub-representação das mulheres no noticiário.

As noções de formação discursiva, enunciado e arquivo (Foucault, 1997), assim como a noção de comentário (Foucault, 1996), orientam a visão que temos de que o noticiário jornalístico participa de uma dinâmica discursiva caracterizada pela retomada de discursos historicamente cristalizados, nos quais a oposição entre masculinidade e feminilidade se mantém e está associada a papéis convencionais de gênero. Esses discursos, ainda que retomados pontualmente, estabelecem os limites para a produção de novos discursos. Isso significa que o que é dito nas revistas não é o mesmo que foi dito décadas antes - e falar em estereótipos não significa falar em permanências intocadas. ${ }^{13}$ Mas é, por outro lado, delimitado por pressupostos e condições que atualizam representações de gênero nas quais a mulher existe em posição de exterioridade ou de marginalidade em relação ao campo político. A negação, freqüente, de que as relações de poder entre homens e mulheres são problemáticas, a presença reduzida das mulheres no noticiário e os estereótipos que serão discutidos a seguir compõem essas retomadas - pontuais, porém produtivas justamente porque ativam representações de gênero que têm efeitos sobre a compreensão da sub-representação feminina na política e sobre as carreiras das mulheres que procuram inserir-se ou manter-se nesse campo.

${ }^{13}$ Em outra vertente, a pesquisa "Gênero e política na mídia brasileira" produz uma análise diacrônica da presença de deputadas, senadoras e ministras nas revistas semanais brasileiras. $\mathrm{O}$ estudo da visibilidade das mulheres políticas ao longo de mais de duas décadas permite observar as transformações, mas indica que existem permanências que não podem ser desconsideradas. 
Flávia Biroli

\subsection{Personalidade e feminilidade}

Em busca de pistas relativas às marcas de gênero existentes no material, das 312 matérias que compõem o corpus da pesquisa, foram selecionadas todas aquelas em que há alguma menção à personalidade das personagens analisadas. Personalidade está sendo entendida, aqui, em sentido bastante amplo: foram selecionadas quaisquer referências a um modo de ser próprio a um determinado indivíduo, que o caracterizaria, incluindo o que se costuma chamar de temperamento, assim como comportamentos, hábitos e gostos.

Em 7\% dos casos (22 matérias) há alguma referência à personalidade. Nesse quesito, Heloisa Helena está à frente das demais, com 14 dessas referências, contra 3 nos casos de Dilma Rousseff e Marta Suplicy e 2 no de Márcio Thomaz Bastos. Feita a seleção desses textos, analisamos os enunciados que constituem essas referências.

Vale destacar, inicialmente, que a única referência ao feminismo em todo o material selecionado aparece nesse segmento do material. Dilma Rousseff, segundo reportagem da revista Carta Capital (19/04/2006, p. 12), seria uma "figura complexa": "é durona, mas é feminina. Sem ser feminista". ${ }^{14}$ A essa afirmação se segue a de que "tem um temperamento forte e é tida como uma negociadora intransigente e técnica", associando à ministra o rótulo de "Dama de Ferro". A reportagem refere-se ao encontro entre Rousseff $e$ a presidente do Chile, Michelle Bachelet, e é intitulada "Jogo de Damas".

\footnotetext{
${ }^{14}$ Outras reportagens que apresentam algum dado, painel ou discussão sobre a presença de mulheres em postos de poder ou sobre o voto de mulheres não mencionam os termos feminismo ou feminista. Ao contrário, parece haver uma supressão significativa desses termos. Há uma referência à posição de Heloisa Helena em um quadro destacado em reportagem da revista Época (14/08/2008, p. 31) que diz: "HH se apresenta como candidata progressista e engajada nas causas femininas. Mas é contra a descriminalização do aborto, principal bandeira dos grupos organizados que lutam pelos direitos das mulheres".
} 
Gênero e política

As referências à personalidade de Heloisa Helena foram feitas em matérias publicadas no segundo semestre de 2006. Em todos os casos, há um entrecruzamento com representações da feminilidade. Um exemplo é a reportagem da revista Veja (26/07/2006, p. 48) dedicada a Heloisa Helena: a então candidata à presidência seria "uma das poucas [mulheres] que gostam de política”. Seu caráter é associado ao afeto, à impulsividade e à honestidade, com críticas ao que seria um radicalismo sem lugar no presente. De um lado, o radicalismo está associado a uma postura "Cabra-Macho" ${ }^{15}$; de outro, sensibilidade, honestidade e suavidade aparecem ligadas a alguma essência feminina ou a representações convencionais da feminilidade. Citamos alguns exemplos: (1) as afirmações de que ela tem caráter, honestidade, integridade e é a antítese do político profissional vêm acompanhadas das afirmações de que "fala sempre como mãe" $e$ tem "aversão à vaidade feminina"; em outro caso, (2) "representa a esperança, lealdade, honestidade, hombridade e respeito pelo próximo; mostra o que há de melhor na essência feminina"; (3) "de perigosa subversiva a suave mulher, a senadora tenta, na campanha, se desvincular da imagem de radical e intransigente"; e, ainda, (4) caracterizada como "mistura de udenista e beata", "esperneante Rosa Luxemburgo", é associada aos adjetivos "fera" e "fofa".

As referências a Marta Suplicy, por sua vez, são interessantes por apresentarem um indício de diferenças no tratamento da problemática de gênero entre as revistas, associado a posições políticas diferentes no contexto em que foram produzidas as reportagens. Das três menções à personalidade de Suplicy, duas estão em Carta Capital e uma em Veja. Em Carta Capital, uma delas está presente na já mencionada reportagem

\footnotetext{
${ }^{15}$ Segundo reportagem publicada pela revista Carta Capital (09/08/2006, p. 20) sobre as estratégias dos candidatos à Presidência, Heloisa Helena estaria dividida entre "manter a postura Cabra-Macho que provocou a ascensão nas pesquisas, mas com efeitos colaterais no quesito rejeição, ou suavizar o discurso".
} 
"Jogo de Damas", que traz a seguinte legenda a uma foto de Suplicy: "Impor-se com feminilidade é meta de Marta Suplicy". Nessa matéria, a voz da atual ministra do Turismo está presente, enunciando que "Há certos momentos em que tenho que ser dura, falar grosso", ao mesmo tempo em que teria dito: "Sou feminina". O segundo caso, na mesma revista, em que a personalidade de Suplicy é citada consiste em uma reportagem que relaciona, de forma crítica, personalidade na esfera pública e feminilidade no contexto da reforma ministerial, mencionando o fato de que homens e mulheres recebem julgamentos diferentes na esfera pública: "Mulher com atitude é histérica e desaforada; homem histérico e desaforado é só alguém cumprindo honradamente seu dever" (Carta Capital, 21/02/2007, p.45).

Já a reportagem da revista Veja (14/03/2007, p.50) apresenta uma Marta Suplicy pouco valorizada por seu partido (o PT). Vale destacar que a visibilidade de Marta Suplicy em Veja se divide entre dois eixos predominantes: (1) a busca por um ministério no início de 2007, em que é retratada como fraca e desprestigiada por Lula, $e(2)$ a associação entre seu nome e denúncias de corrupção, envolvendo integrantes de sua equipe na Prefeitura de São Paulo. A essa visibilidade associam-se clichês de gênero, como a caracterização da já ministra Marta Suplicy como "sexóloga e ministra do Turismo 'sexual", na coluna Veja essa (20/06/2007, p.52) $)^{16}$, e uma associação entre Suplicy e Rosinha Matheus, afirmando que ambas teriam entrado na política "graças ao prestígio político dos seus maridos". ${ }^{17}$

Thomaz Bastos, personagem menos caracterizada no que se refere à personalidade, permite um contraponto interessante com as personagens femininas analisadas. É caracterizado de duas

\footnotetext{
${ }^{16}$ Marta Suplicy é assim rotulada, logo abaixo do destaque a sua consideração durante episódios de crise nos aeroportos brasileiros: "Relaxa e goza porque você esquece todos os transtornos depois (ao chegar ao destino)".

${ }^{17}$ Essa matéria foi publicada em 15/02/2006 e será discutida mais adiante, na seção Vida privada.
} 
Gênero e política

formas: (1) econômico, em caracterização irônica (ao mobiliar seu apartamento, orienta os decoradores a negociar os preços dos móveis, mas chega a pagar 11 mil reais em um tapete, segundo reportagem publicada em Veja (14/02/2007, p.38); (2) "pode ser muitas coisas, menos ingênuo", afirmação que, no contexto das denúncias de corrupção, pode ganhar conotação negativa (não está dizendo a verdade, sabe e mente), mas que o coloca em uma posição bastante diferente daquelas em que são colocadas as três mulheres - aqui, pode-se dizer, predominam racionalidade $e$ astúcia (mesmo que não honestidade).

Fica indicada, mais uma vez, a hipótese de que as menções ao ministro Márcio Thomaz Bastos estão associadas a representações de masculinidade que funcionam como contraponto significativo às representações de feminilidade presentes no material. Voltaremos a essa hipótese nos próximos itens.

\subsection{Corporalidade}

Entre as revistas analisadas no período pesquisado foi selecionado todo material que traz referências aos corpos das personagens, com destaque para a aparência física. Entende-se que a mera referência ao corpo indica um modo de enquadrar a existência pública dessas personagens. A análise dos enunciados que constituem essas referências permite uma compreensão maior das conexões entre corporalidade e outros elementos que organizam as divisões de gênero no noticiário das revistas.

Em apenas 3,2\% do material (10 matérias) há menções à aparência física das personagens analisadas. Vale ressaltar que, no período analisado, não há qualquer menção à aparência física do ministro Márcio Thomaz Bastos.

Há apenas uma menção indireta à aparência da ministra Dilma Rousseff. Trata-se de uma referência, na coluna "Radar", ao fato de que a ministra estaria fazendo uma dieta para perder peso (Veja, 22/02/2006, p.37). Vale observar que um 
desdobramento da pesquisa, no qual é feita a análise da visibilidade das ministras brasileiras nas revistas semanais, permite observar que quando Rousseff ganha mais visibilidade em 2008 suas representações são mais marcadas pela problemática de gênero e a relação entre competência pública e feminilidade se estabelece de forma mais clara. Além de caracterizações como "mãe do PAC" e "Geisel de saias", reproduzidas pelas revistas, a possibilidade de que seja candidata à Presidência abre toda uma agenda da corporalidade nas reportagens: multiplicam-se os comentários relacionados à aparência, especialmente referentes a dietas alimentares para emagrecer, tendo como exemplo mais acabado da visibilidade dada ao corpo feminino, entrevistas com um cirurgião plástico (que recomenda um tratamento com laser para rejuvenescer) e com uma consultora de moda (que recomenda mudanças nas roupas, cabelo e óculos). ${ }^{18}$

No caso de Marta Suplicy, duas reportagens trazem referências à aparência física. Uma delas menciona o fato de que ela se apresenta em público "invariavelmente de tailleur ou vestido". Esse enunciado está presente na revista Veja (04/04/2007, p.74), em uma nota na seção "Gente" e não no noticiário político. Está ao lado de uma nota sobre a filha de Guido Mantega, Marina Mantega, que seria namorada de um diretor da Globo e estaria aguardando um convite para participar de uma novela da emissora. A nota trata da primeira semana de Suplicy como ministra do Turismo, fala de longas jornadas de trabalho, menciona o fato de estar sempre de tailleur ou vestidos e traz uma foto da ministra em ângulo que permite que se vejam suas pernas e cocha. Em outra reportagem (Época, 21/08/2006, p.33), dedicada a projeções sobre o comportamento eleitoral das mulheres nas eleições de 2006, atribui-se à cientista política Lúcia Hipólito a

${ }^{18}$ Época, 21/04/2008, p. 57. A matéria apresenta, ainda, o "conselho" do publicitário Lula Vieira: Dilma deveria transformar o "jeito durão" em "estilo mãe" Em janeiro de 2009, a ministra submeteu-se a cirurgias plásticas com o objetivo de obter uma aparência considerada mais adequada às disputas eleitorais de 2010. 
Gênero e política

opinião de que não existe "voto de gênero". Nas palavras atribuídas a Hipólito, "Marta Suplicy, na Prefeitura de São Paulo, teve enorme rejeição entre as mulheres com seu estilo Chanel na lama".

As referências a Heloisa Helena, presentes em maior quantidade, indicam uma relação proporcional entre visibilidade $e$ marcas de gênero, como no caso de Dilma Rousseff. São várias as referências: (1) retomadas de caracterizações e julgamentos sobre um visual considerado simples demais para uma candidata à Presidência, associando "pureza socialista", "vitória da calça jeans e rabo-de-cavalo" e propostas de governo que resultariam em uma catástrofe para o país, caso fossem implementadas (Veja, 26/07/2006, p.48); ou ainda, em Carta Capital (13/9/2006, p.21), "a $\mathrm{HH}$, da blusinha branca, do blue jeans e do vernáculo em chamas" é vinculada a caracterizações da feminilidade, "com seu figurino propositalmente casto, a Che Guevara de saias"; (2) uma observação fina da aparência - os longos cabelos presos em rabode-cavalo como marca registrada ou, mais raramente, "cabelo solto, encaracolado à custa de baby liss e levemente esvoaçante", sobrancelhas recém-acertadas, cilios pintados (longos), maquiagem 'bem natural'", como descreve uma nota na coluna Gente (Veja, 01/03/2006, p. 63) sobre o tratamento dado à aparência de Heloisa Helena em fotos para a seção Visual Novo da revista Cláudia; (3) observações que tornam visível o corpo, sexualizando a presença da mulher na esfera pública - "seu corpo é de carne pouca", tem "pernas bem feitas" -, ao mesmo tempo em que a vinculam à maternidade e a família, ao caracterizá-la como "mãe leoa", que "fala sempre como mãe" (Época, 14/08/2006, p.29-34). ${ }^{19}$ Há, ainda, afirmações como a de que a

${ }^{19}$ Vale registrar o seguinte trecho da reportagem publicada em Época (14/8/2006, pp.29-34), que traz perfil de Heloisa Helena escrito por Ruth de Aquino: "Estilo agri-doce, morde-e-assopra. Fala, sempre, como mãe. Mãe leoa, marxista e cristã, enfermeira e professora. Seu modelito - camisa branca de algodão com babadinhos, jeans desbotado e sandália plataforma com meia não corre o menor perigo de virar moda. Só combina com o jeito $\mathrm{HH}$ de ser. 
"cara de professora" seria sua marca registrada, dita, supostamente, pela própria candidata (Veja, 01/03/2006, p.63).

Vale ressaltar que está presente aqui uma das tensões ligadas à representação de mulheres na esfera pública, especialmente na esfera de visibilidade midiática: as referências à aparência física e a aspectos entendidos como vinculados à feminilidade podem constituir um obstáculo, ao reforçarem uma visão estigmatizada (a comparação com Márcio Thomaz Bastos pode indicar que essa é uma questão relevante, uma vez que não há qualquer menção à aparência física no caso do ministro), mas também podem ser um recurso para a construção de uma identidade diferenciada da dos homens, ou uma estratégia para conquistar visibilidade.

Essa tensão remete a um problema mais amplo. Por um lado, o apagamento das marcas de gênero pode reforçar uma concepção universal de indivíduo que nega que as diferenciações existem socialmente e que as relações de poder são perpassadas pelo gênero. Por outro lado, a presença enquanto mulheres, vinculada a estereótipos que remetem à maternidade e à sexualidade, para citar apenas dois exemplos, remete a representações convencionais e restritivas, naturalizadas nas reportagens. A exigência difusa de que as mulheres se comportem enquanto homens quando se encontram em posições de maior destaque, ou para que a elas tenham acesso, convive com a exigência de que as mulheres se comportem enquanto mulheres. Nos dois casos, mantêm-se critérios androcêntricos para o julgamento do comportamento feminino, que atam as mulheres a comportamentos convencionais ou as restringem a

Serve para marcar a aversão à vaidade feminina e facilitar o trabalho dos chargistas". Na mesma reportagem, "dois desafios parecem intransponíveis: convencer Heloisa a não esconder as pernas bem-feitas e a soltar os cabelos. 'Minha filha', disse ela, 'se eu soltar os cabelos pra foto vão dizer que não sou a mesma; depois de ter filho, para amamentar e andar de ônibus, só dá pra andar de rabo-de-cavalo". 
Gênero e política

comportamentos considerados legítimos em esferas predominantemente masculinas.

\subsection{Vida privada}

As referências à vida privada das personagens consistem em menções a aspectos da vida entendidos comumente como do âmbito pessoal, íntimo, doméstico, afetivo, não-público. ${ }^{20}$

Ao todo, as referências à vida privada estão em 5,76\% do material (18 matérias). Entre elas, há 9 menções a familiares.

Vale ressaltar que não há nenhuma referência a familiares no caso de Márcio Thomaz Bastos, repetindo o que ocorre no eixo anterior, em que apenas no caso do ministro não havia qualquer referência à aparência física. As referências a sua vida anterior e/ou distinta de suas funções como ministro remetem à sua posição profissional (profissional bem-sucedido, advogado criminalista de sucesso, com "carreira invejável no campo estritamente criminal, que se expressou tanto em prestígio quanto em patrimônio") e à amizade com poderosos, como Antonio Carlos Magalhães. Bastos é caracterizado como alguém que, antes dos escândalos do governo Lula, seria dono da tranqüilidade $e$ simpatia espontâneas dos profissionais bem-sucedidos e dos homens felizes na sua vida pessoal (Veja, 31/05/2006, p.40). Na mesma reportagem, há uma referência à alimentação $e$ aos gostos pessoais, ao ser caracterizado como "apreciador de boa literatura, pintura moderna e bons vinhos". Esse quadro de referências difere de maneira relevante das referências a casamento, maternidade, roupas e dietas no caso das mulheres analisadas. Parece haver uma relação entre representações da competência masculina na esfera pública e representações da masculinidade que exclui, de maneira significativa, a vida familiar e afetiva.

\footnotetext{
${ }^{20}$ Nesta análise, não fazemos distinções entre essas categorias e as tomamos tais como se apresentam nos textos analisados.
} 
No caso da ministra Dilma Rousseff, as referências são a sua formação como economista e a sua competência técnica, aos amigos dos tempos de combate à ditadura militar, mas também a sua idade, a sua filha, ao fato de ser divorciada e a uma dieta alimentar. Junto com a publicação de uma entrevista com a ministra, a revista Época (30/01/2006, p. 24) menciona a cidade natal da ministra $e$ o fato de ser divorciada e ter uma filha. Como "curiosidade", menciona o fato de gostar de "pintura e cultura chinesa".

No caso de Marta Suplicy, há referências pontuais ao marido, o publicitário Luis Favre, e uma referência velada ao exmarido (senador Eduardo Suplicy). Veja (15/02/2006, p.48) associa Suplicy a Rosinha Garotinho à estrela dessa reportagem, a primeira-dama de Salvador, Maria Luíza. Após caracterizar Maria Luíza de maneira bastante irônica, ridicularizando sua influência sobre o marido, apresenta o seguinte enunciado: "Assim como Rosinha Matheus e Marta Suplicy, que também entraram na política graças ao prestígio político dos seus maridos, Maria Luíza prepara-se para alçar vôos mais altos". Nesse caso, Veja recorre a uma inverdade para atingi-la, o que pode ser visto em um quadro mais amplo das posições e práticas de Veja em relação às lideranças do PT.

Mais uma vez, é no caso de Heloisa Helena que as referências se multiplicam. Por ter disputado as eleições de 2006, há referências a seu patrimônio, a sua origem e carreira como professora universitária na UFAL, mas também a suas relações com a mãe, os irmãos, os filhos e a maternidade. A revista menciona, rapidamente, um suposto affair com o ex-senador Luis Estevão, envolvido em denúncias de corrupção. O que predomina no material é, no entanto, uma forte acomodação entre os enquadramentos de gênero presentes na mídia e as estratégias da candidata. Segundo o material analisado, é a própria Heloisa Helena que se refere inúmeras vezes à maternidade - teria prometido, por exemplo, "acolher todas as crianças e jovens da maneira como acalenta seus filhos" (Época, 14/08/2006, p.34). Esse 
Gênero e política

aspecto de sua auto-apresentação, ressaltado no material jornalístico, colabora para uma vinculação entre a atuação pública de mulheres e uma identidade feminina cristalizada e redutora.

Ressalta-se, novamente, que as menções ao ministro Márcio Thomaz Bastos estão associadas a representações de masculinidade que funcionam como contraponto significativo às representações de feminilidade presentes no material. Há um conjunto distinto de referências (ou de silêncios), que permitem falar na presença de estereótipos de gênero.

\section{Considerações finais}

Existem marcas de gênero na maneira como as personagens analisadas estão representadas no noticiário? Se sim, pode-se falar em estereótipos de gênero? As análises indicam que a resposta é positiva nos dois casos.

Ressaltamos a relevância do controle feito por meio da análise das representações do então ministro Márcio Thomaz Bastos. Essa comparação permitiu observar que algumas das marcas, quantitativamente restritas, são parte de séries discursivas que demarcam um conjunto de referências para o julgamento da atuação feminina em qualquer esfera, estabelecendo continuidades entre um papel que seria reservado às mulheres na vida privada (mãe, mulher afetiva e zelosa com a própria aparência) e o papel que teriam na vida pública. A especificidade de sua atuação na política estaria justamente em colocar em relevo esse "fundo comum" - um denominador comum feminino acompanhado de julgamentos que estabelecem as divisões entre comportamento adequado e inadequado.

Assim, é possível perceber uma oscilação entre uma expectativa de que a mulher se apresente, na política, enquanto mulher, e um conjunto de julgamentos referenciados pela presença masculina na política $e$ por representações da masculinidade, conectando a competência na esfera pública a atitudes entendidas como masculinas ou masculinizadas. 
A partir da discussão feita por Carole Pateman (1990), podese dizer que as mulheres vêm sendo excluídas e incluídas na esfera pública enquanto mulheres, isto é, pelas significações e formas de valorização associadas ao que se entende como feminilidade noção definida, predominantemente, em relação às representações hegemônicas da masculinidade. Da perspectiva que assumimos, é preciso levar em consideração que o recurso aos papéis sociais tradicionalmente reservados às mulheres pode ser, ao mesmo tempo, um obstáculo a uma atuação política mais destacada $e$ uma estratégia de diferenciação $e$ ação política por parte das mulheres.

Estratégias diferenciadas podem levar a identidades de gênero também distintas. As diferenças entre as representações das três mulheres analisadas são resultado de suas trajetórias pessoais, de suas carreiras e diferentes formas de inserção na vida pública, de formas diferenciadas de "gestão" de sua visibilidade. No noticiário analisado, porém, essas identidades distintas são conectadas em discursos comuns sobre a feminilidade e sobre as relações entre mulheres e política. Encontram-se, assim, em um campo comum - o das representações estereotipadas de feminilidade -, o que é explicitado, na análise, pelo contraponto com as representações do então ministro Márcio Thomaz Bastos.

A presença restrita, do ponto de vista quantitativo, de estereótipos de gênero deve ser compreendida no contexto mais amplo da invisibilidade feminina no noticiário. Como mostram as pesquisas realizadas, a forma atual da divisão entre os sexos no noticiário político das revistas semanais brasileiras reserva às mulheres a invisibilidade, combinada a uma presença marginal, isto é, vinculada a áreas e temáticas de menor prestígio político no noticiário. Sua presença é, assim, reduzida, concentrada em poucas mulheres e acompanhada por marcas quantitativamente restritas, porém significativas, que remetem a estereótipos de gênero que atualizam divisões convencionais entre masculinidade e feminilidade. 
Gênero e política

\section{Referências bibliográficas}

BIROLI, Flávia. Gênero e família em uma sociedade justa: adesão e crítica à imparcialidade no debate contemporâneo sobre justiça. Revista de Sociologia e Política, vol. 18, n 36, 2010.

e MELLO, Janine. Gênero e representação política: limites e apostas das deputadas federais na 52 ${ }^{\text {a }}$ Legislatura (2003-2006). Paper apresentado no VI Encontro da Rede Brasileira de Estudos e Pesquisas Feministas (Redefem), Belo Horizonte, UFMG, 2008.

CARROL, Susan J. e SCHREIBER, Ronnee. Media coverage of women in the 103rd Congress. In: NoRRIS, Pippa. (ed.) Women, media and politics. New York/Oxford, Oxford University Press, 1997, pp.131148.

FouCAULT, Michel. A arqueologia do saber. $5^{\mathrm{a}}$ ed. Rio de Janeiro, Forense Universitária, 1997.

A ordem do discurso. São Paulo, Ed. Loyola, 1996.

FRASER, Nancy. Beyond the master/subject model: on Carole Pateman's The sexual contract. In: Justice interruptus: critical reflections on the "postsocialist" condition. New York, Routledge, 1997, pp.225-235.

IYENGAR, Shanto; VALENTINO, Nicholas A.; ANSOLABEHERE, Stephen; SIMON, Adam F. Running as a woman: Gender stereotyping in political campaign. In: NORRIS, Pippa. (ed.) Women, media and politics. New York/Oxford, Oxford University Press, 1997, pp.77-98.

MigUEL, Luis Felipe e BIROLI, Flávia. A produção da imparcialidade: a construção do discurso universal a partir da perspectiva jornalística. Revista Brasileira de Ciências Sociais, vol. 25, nº 73, 2010.

Mídia e representação política feminina: hipóteses de pesquisa. Revista Opinião Pública, vol. 15, nº 1, 2009.

Gênero e política no jornalismo brasileiro. Revista Famecos, $n^{\circ}$ 36, Porto Alegre, 2008, pp.24-39.

MOUFFE, Chantal. Feminism, citizenship and radical democratic politics. In: The return of the political. London, New York, Verso, 2005, pp.74-89.

NoRRIS, Pippa. Introduction: Women, Media and Politics. In: NoRRIS, P. (ed.) Women, media and politics. New York/Oxford, Oxford University Press, 1997, pp.1-18. 
OKIN, Susan. Justice, gender, and the family. New York, Basic Books, 1989.

. Gender, the public and the private. In: PHILLIPS, Anne. (ed.) Feminism and politics. Oxford, Oxford University Press, 1998, pp.116-41.

PATEMAN, Carole. O contrato sexual. Rio de Janeiro, Paz e Terra, 1993.

Does sex matter to democracy? Scandinavian political studies, vol. 13, n 1, 1990, pp.57-63.

PÊCHEUX, Michel. Análise automática do discurso. In: GADET, F. e HAK, T. (orgs.) Por uma análise automática do discurso. Campinas-SP, Ed. Unicamp, 1997, pp.61-162.

PINHEIRO, Luana S. Vozes femininas na política: uma análise sobre mulheres parlamentares no pós-Constituinte. Brasília, Secretaria Especial de Políticas para as Mulheres, 2007.

PHILIPS, Anne. Politics of Presence. Oxford, Clarendon Press, 1995.

THOMPSON, John B. Ideologia e cultura moderna: teoria social crítica na era dos meios de comunicação de massa. Petrópolis, Vozes, 1995.

YOUNG, Iris M. Inclusion and democracy. Oxford, Oxford University Press, 2000. 